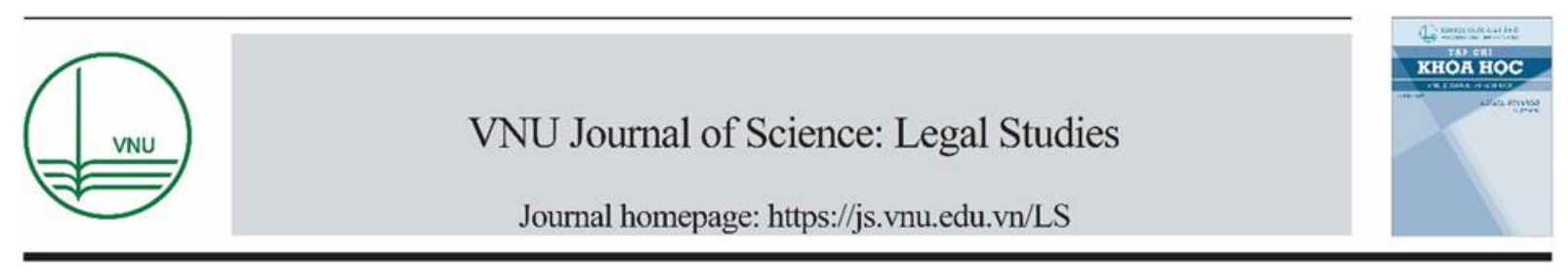

Review Article

\title{
Vietnam's Labour Law from the Perspective of the Comprehensive and Progressive Agreement for Trans-Pacific Partnership
}

\author{
Le Thi Hoai Thu* \\ VNU School of Law, 144 Xuan Thuy, Cau Giay, Hanoi, Vietnam
}

Received 15 June 2019

Revised 25 July 2019; Accepted 19 September 2019

\begin{abstract}
The ratification of the Comprehensive and Progressive Agreement for Trans-Pacific Partnership (CPTPP) is a chance for the economic development of Vietnam. This Agreement also entails demand for legal amendment, including legal regulations on labour. This article analyzes the member states' commitments to the labour issues stipulated in this Agreement, and then compares them with the corresponding Vietnam's regulations for determining the level of compatibility between them to propose some recommendations for enhancing the compatibility.
\end{abstract}

Keywords: CPTPP, labour regulations.

\footnotetext{
* Corresponding author.

E-mail address:le_hoai_thu2002@yahoo.co.uk
}

https://doi.org/10.25073/2588-1167/vnuls.4238 


\title{
Thực trạng pháp luật lao động việt Nam hiện nay dưới góc nhìn tham chiếu với Hiệp định Đối tác toàn diện và tiến bộ xuyên Thái Bình Dương
}

\author{
Lê Thị Hoài Thu* \\ Khoa Luật, Đại học Quốc gia Hà Nội, 144 Xuân Thủy, Cầu Giấy, Hà Nội, Việt Nam \\ Nhận ngày 15 tháng 6 năm 2019 \\ Chỉnh sửa ngày 25 tháng 7 năm 2019; Chấp nhận đăng ngày19tháng9năm 2019
}

\begin{abstract}
Tóm tắt: Việc tham gia Hiệp định Đối tác toàn diện và tiến bộ xuyên Thái Bình Dương là một cơ hội lớn cho sự phát triển của nền kinh tế của Việt Nam. Bên cạnh đó, Hiệp định này cũng tạo ra những yêu cầu về điều chỉnh pháp lý, trong đó có quy định về pháp luật lao động. Bài viết sẽ tập trung phân tích những cam kết của các quốc gia thành viên trong lĩnh vực lao động thể hiện trong Hiệp định, từ đó đối chiếu so sánh với nội luật để xác định tính tương thích, từ đó đề xuất một số giải pháp tăng cường sự tương thích đó.
\end{abstract}

Tù khóa: Hiệp định CPTPP, pháp luật lao động.

\section{Khái quát chung về cam kết lao động trong Hiệp định Đối tác toàn diện và tiến bộ xuyên Thái Bình Dương}

Hiệp định Đối tác Xuyên Thái Bình Dương (TPP) là Hiệp định thương mại tự do được đàm phán từ tháng $3 / 2010$, bao gồm 12 nước thành viên là Hoa Kỳ, Canada, Mexico, Peru, Chile, New Zealand, Australia, Nhật Bản, Singapore, Brunei, Malaysia và Việt Nam. TPP được chính

\footnotetext{
* Tác giả liên hệ.

Địa chỉ email:1e_hoai_thu2002@yahoo.co.uk

https://doi.org/10.25073/2588-1167/vnuls.4238
}

thức ký ngày 04/02/2016 và được dự kiến sẽ có hiệu lực từ 2018. Tuy nhiên, đến tháng 01/2017, Hoa Kỳ tuyên bố rút khỏi TPP, khiến TPP không thể đáp ứng điều kiện có hiệu lực như dự kiến ban đầu. Tháng 11/2017, 11 nước thành viên TPP ra Tuyên bố chung thống nhất đổi tên TPP thành Hiệp định Đối tác Toàn diện và Tiến bộ Xuyên Thái Bình Dương (CPTPP). СРTPP được chính thức ký kết vào tháng 3/2018 bởi 11 nước thành viên còn lại của TPP (không bao gồm Hoa Kỳ) ${ }^{1}$. CPTPP sẽ có hiệu lực nếu ít nhất 6 nước hoặc một nửa số thành viên CPTPP phê chuẩn Hiệp định này. CPTPP giữ nguyên gần như toàn bộ các cam kết của

\footnotetext{
${ }^{1}$ Australia, Brunei, Canada, Chile, Nhật Bản, Malaysia, Mexico, New Zealand, Peru, Singapore và Việt Nam.
} 
TPP, ngoại trừ: (i) Các cam kết của Hoa Kỳ hoặc với Hoa Kỳ; (ii) 22 điểm tạm hoãn; (iii) Một số sửa đổi trong các Thư song phương giữa các Bên của CPTPP [1]. Đối với Việt Nam, Quốc hội đã thông qua Nghị quyết về việc phê chuẩn Hiệp định CPTPP và các văn kiện có liên quan vào ngày 12/11/2018. Theo đó, Hiệp định sẽ có hiệu lực đối với Việt Nam kể từ ngày 14/01/2019.

Các quy định tại Chương 19 của CPTPP về quan hệ lao động, ảnh hưởng trực tiếp đến chính sách pháp luật nói chung và chính sách pháp luật lao động nói riêng của các quốc gia bao gồm 4 nội dung sau: (1) Cam kết chung về quyền lao động; (2) Trách nhiệm xã hội của doanh nghiệp; (3) Nhận thức cộng đồng và sự đảm bảo về thủ tục; (4) Sự tham gia của công chúng vào việc xây dựng, thực thi chính sách pháp luật lao động. Các nội dung còn lại được quy định tại Chương 19 là các vấn đề liên quan đến cơ chế đảm bảo thực thi Hiệp định. Trong 4 nhóm nội dung nêu trên, "Cam kết chung về quyền lao động" là nhóm nội dung liên quan và tác động trực tiếp tới pháp luật lao động nước ta. Sau đây là đánh giá khái quát tính tương thích của pháp luật lao động Việt Nam dưới góc độ tham chiếu với CPTPP theo nhóm nội dung "Cam kết chung về quyền lao động".

Cam kết chung về quyền lao động được coi là nội dung trung tâm và quan trọng nhất của Chương 19 Hiệp định. Tất cả các quy định khác của Chương này suy cho cùng cũng là để đảm bảo thực thi các quyền lao động tại các quốc gia thành viên của Hiệp định một cách hiệu quả nhất.

Các quyền lao động mà các Bên của Hiệp định cam kêt thực hiện trong quan hệ lao động tại quốc gia mình bao gồm: (i) Tự do hiệp hội và thực hiện có hiệu quả quyền thương lượng tập thể; (ii) Xóa bỏ mọi hình thức lao động cưỡng bức và lao động bắt buộc; (iii) Xóa bỏ có hiệu quả lao động trẻ em và nghiêm cấm các hình thức lao động trẻ em tồi tệ nhất; (iv) Xóa bỏ phân biệt đối xử trong công việc. Đây không phải là những nội dung mới về tiêu chuẩn lao động quốc tế, mà là sự tiếp tục khẳng định các quyền lao động đã được ghi nhận trong Tuyên bố năm 1998 và được quy định trong 08 công ước cơ bản của Tổ chức Lao động quốc tế (Việt Nam đã phê chuẩn 06/08 công ước $)^{2}$.

Về cơ bản, những nội dung của 06 công ước cơ bản mà Việt Nam đã phê chuẩn đã được nội luật hóa và tổ chức thực hiện trên thực tế ở những mức độ khác nhau. Các quy định của pháp luật lao động Việt Nam cũng đã tương thích một phần với 02 công ước cơ bản Việt Nam chưa phê chuẩn (Công ước số 87 và Công ước số 105).

\section{Tính tương thích của pháp luật lao động Việt Nam dưới góc độ tham chiếu với Hiệp định Đối tác toàn diện và tiến bộ xuyên Thái Bình Dương}

\subsection{Quyền tư do hiệp họi và thưc hiện có hiệu quả quyền thuoong luợng tập thể}

\section{Thư nhất, về quyền tư do hiẹp hội}

Cùng với quyền thành lập, gia nhập, hoạt động công đoàn của người lao động được ghi nhận tại Bộ luật lao động năm 2012 và được quy định chi tiết tại Luật Công đoàn năm 2012, quyền tự do hiệp hội của người sử dụng lao động cũng được quy định tại các văn bản quy phạm pháp luật về hội [2], được đề cập ngày càng rõ nét hơn trong Bộ luật lao động và các

\footnotetext{
${ }^{2} 08$ công ước cơ bản của ILO gồm: Công ước số 87 (năm 1948) về tự ho hiệp hội và bảo vệ quyền tổ chức; Công ước số 98 (năm 1949) về quyền tổ chức và thương lượng tập thể; Công ước số 29 (năm 1930) về xóa bỏ lao động cưỡng bức; Công ước số 105 (năm 1957) về xóa bỏ lao động cưỡng bức; Công ước số 100 (năm 1951) về trả công bình đẳng giữa lao động nam và lao động nữ; Công ước số 111 (năm 1958) về chống phân biệt đối xử trong công việc; Công ước số 138 (năm 1973) về độ tuổi tối thiểu trong lao động; Công ước số 192 (năm 1999) về xóa bỏ các hình thức lao động trẻ em tồi tệ nhất. Việt Nam đã phê chuẩn Công ước số 100 và Công ước số 111 vào năm 1997, Công ước số 182 vào năm 2000, Công ước số 138 vào năm 2003, Công ước số 29 vào năm 2007, Công ước số 98 năm 2019.
} 
văn bản quy định chi tiết, hướng dẫn thi hành Bộ luật lao động. Theo đó, đại diện của người lao động Việt Nam hiện nay có một tổ chức duy nhất là tổ chức Công đoàn Việt Nam (thuộc hệ thống của Tổng Liên đoàn lao động Việt Nam), tổ chức đại diện của người sử dụng lao động chủ yếu gồm: Phòng Thương mại và Công nghiệp Việt Nam (VCCI); Liên minh các hợp tác xã Việt Nam (VCA); Hiệp hội các doanh nghiệp nhỏ và vừa Việt Nam (VINASME).

Từ góc nhìn tham chiếu với CPTPP, cụ thể hơn là với Công ước số 87 (năm 1948) của ILO [3], có thể thấy những điểm chưa tương thích của pháp luật Việt Nam như sau:

- Về quyền thành lập, gia nhập công đoàn của mọi đối tượng người lao động.

Theo quy định tại Điểm $\mathrm{c}$ Khoản 1 Điều 5, Khoản 1 Điều 189 Bộ luật lao động 2012, Khoản 1 Điều 5 Luật Công đoàn 2012 chỉ những người lao động Việt Nam làm việc trong cơ quan, tổ chức, doanh nghiệp mới có quyền thành lập, gia nhập và hoạt động công đoàn. Như vậy, so với tiêu chuẩn quốc tế, luật pháp Việt Nam đã loại trừ một số đối tượng người lao động mà đáng ra họ cũng phải có quyền thành lập và gia nhập công đoàn, bao gồm: i) người lao động không phải là người có quốc tịch Việt Nam làm việc tại Việt Nam; ii) người lao động trong khu vực phi chính thức, người lao động tự do, không có quan hệ việc làm; iii) người lao động làm việc cho cá nhân, hộ gia đình (không phải là "cơ quan, tổ chức, doanh nghiệp" theo quy định tại Khoản 1 Điều 5 Luật Công đoàn) [4].

- Về quyền thành lập công đoàn theo sự lựa chọn của chính người lao động.

Theo Khoản 1 Điều 189 Bộ luật lao động 2012 và Khoản 2 Điều 5 Luật Công đoàn 2012, trình tự, thủ tục thành lập, gia nhập và hoạt động Công đoàn theo quy định của Điều lệ Công đoàn Việt Nam. Khoản 3 Điều 188 Bộ luật lao động 2012 quy định ở những nơi chưa thành lập tổ chức công đoàn cơ sở, công đoàn cấp trên trực tiếp cơ sở thực hiện vai trò đại diện cho tập thể người lao động.
Mặc dù không có quy định nào của ILO về việc phải có bao nhiêu công đoàn ở một quốc gia, có một hay nhiều công đoàn trong một doanh nghiệp. Điều đó cho thấy việc trên thực tế chỉ có một tổ chức công đoàn duy nhất ở cấp quốc gia cũng như chỉ có một công đoàn cơ sở trong một doanh nghiệp không bị coi là trái với tiêu chuẩn quốc tế về quyền tự do hiệp hội nếu đó là kết quả mong muốn thực sự của chính những người lao động. Nó sẽ bị coi là trái với tiêu chuẩn quốc tế về quyền tự do hiệp hội nếu luật pháp có những quy định dẫn đến vị trí độc tôn của một tổ chức công đoàn đã tồn tại ${ }^{3}$. Thực chất, các quy định của Bộ luật lao động và Luật Công đoàn Việt Nam đã xác định vị thế độc tôn của Tổng Liên đoàn lao động Việt Nam. Do vậy, đây là nội dung chưa tương thích với Công ước 87 về tự do hiệp hội.

Quyền tự do hiệp hội, tự do liên kết của người lao động bao gồm cả quyền muốn có tổ chức đại diện hay không, nếu có thì tổ chức đại diện đó là tổ chức đại diện nào là do người lao động tự quyết định. Do đó, quy định của Bộ luật lao động năm 2012 ở những nơi chưa thành lập tổ chức công đoàn cơ sở, công đoàn cấp trên trực tiếp cơ sở đương nhiên thực hiện vai trò đại diện cho tập thể người lao động cuñng được coi là chưa phù hợp với tiêu chuẩn quốc tế về vấn đề này.

- Về vấn đề thành lập công đoàn mà không phải xin phép trước.

Hiện tại, Việt Nam chỉ có một hệ thống công đoàn là Tổng Liên đoàn lao động Việt Nam nên luật pháp hiện hành không có các quy định về điều kiện, trình tự, thủ tục thành lập công đoàn (những việc này được thực hiện theo

\footnotetext{
${ }^{3}$ Từ việc xem xét các vụ khiếu kiện trên thực tế, các ủy ban chuyên gia của ILO đã ra các quyết định nêu rõ: Quy định của luật không cho phép thành lập tổ chức công đoàn thứ hai trong một doanh nghiệp là không phù hợp với Điều 2 Công ước số 87 , theo đó, NLĐ có quyền thành lập và tham gia các tổ chức theo sự lựa chọn của chính mình mà không phải xin phép trước. Các quy định về một tổ chức công đoàn đơn nhất trong mỗi doanh nghiệp, trong mỗi ngành, nghề đều không phù hợp với Điều 2 Công ước số 87 (Bộ Tổng tập của Uy ban ILO về Tự do hiệp hội, năm 2006, đoạn 313-317).
} 
Điều lệ Công đoàn Việt Nam). Tuy nhiên, nếu để thực hiện theo các yêu cầu của Công ước 87 thì Bộ luật lao động và các bộ luật, luật liên quan cần quy định cơ chế để người lao động có thể đăng ký thành lập công đoàn với Nhà nước theo các điều kiện, trình tự và thủ tục hợp lý, công khai và minh bạch.

- Về quyền của người lao động trong việc bầu đại diện của mình một cách tự do.

Tương tự như quyền tự do thành lập công đoàn mà không phải xin phép trước, Bộ luật lao động và Luật công đoàn Việt Nam không quy định việc bầu cử của công đoàn (việc bầu cử công đoàn được thực hiện theo Điều lệ Công đoàn Việt Nam). Tuy nhiên, để thực thi đầy đủ các nội dung của Công ước 87 , Nhà nước cần có những quy định mang tính nguyên tắc về bầu cử công đoàn.

- Về quyền tự chủ, tự quản về tài chính, tài sản công đoàn.

Bộ luật lao động không có quy định về tài sản, tài chính của công đoàn. Vấn đề này được quy định tại Luật Công đoàn cho tổ chức công đoàn duy nhất là Tổng Liên đoàn Lao động Việt Nam. Điều 26 Luật Công đoàn quy định về bốn nguồn thu tài chính công đoàn ${ }^{4}$, trong đó ngoài đoàn phí còn có kinh phí công đoàn $2 \%$ do người sử dụng lao động đóng và tài chính do ngân sách nhà nước hỗ trợ.

Việc quản lý và sử dụng tài chính công đoàn cũng được quy định khá cụ thể tại Điều 27 Luật Công đoàn, trong đó đáng chú ý là Luật quy định việc quản lý, sử dụng tài chính công đoàn vừa theo quy định của pháp luật vừa theo quy định của Tổng Liên đoàn lao động Việt Nam mà không có sự phân biệt về cơ chế quản lý tài chính giữa nguồn kinh phí từ đoàn phí và nguồn từ kinh phí công đoàn.

\footnotetext{
${ }^{4}$ Tài chính công đoàn gồm các nguồn thu: i) Đoàn phí công đoàn do đoàn viên công đoàn đóng theo quy định của Điều lệ Công đoàn Việt Nam; ii) Kinh phí công đoàn do cơ quan, tổ chức, doanh nghiệp đóng bằng $2 \%$ quỹ tiền lương làm căn cứ đóng bảo hiểm xã hội cho người lao động; iii) Ngân sách nhà nước cấp hỗ trợ; iv) Nguồn thu khác từ hoạt động văn hóa, thể thao, hoạt động kinh tế của Công đoàn; từ đề án, dự án do Nhà nước giao; từ viện trợ, tài trợ của tổ chức, cá nhân trong nước và nước ngoài.
}

Điều luật cũng quy định khá cụ thể về mục đích sử dụng tài chính công đoàn vào các công việc cụ thể, trong đó có khá nhiều việc là thuộc chức năng chính trị-xã hội của công đoàn như tuyên truyền đường lối của Đảng, pháp luật của Nhà nước, tổ chức các phong trào thi đua...

Về cơ chế kiểm tra, giám sát tài chính công đoàn, Điều 29 Luật Công đoàn cũng có quy định khá cụ thể, theo đó, ngoài cơ chế tự kiểm tra của công đoàn, cơ quan nhà nước có thẩm quyền cũng có quyền giám sát, thanh tra, kiểm tra, kiểm toán việc quản lý, sử dụng tài chính công đoàn.

Báo cáo rà soát pháp luật Việt Nam với các tiêu chuẩn lao động quốc tế do Văn phòng ILO tại Hà Nội thực hiện tháng 11/2014 đã chỉ ra những điểm chưa tương thích giữa những quy định nêu trên của pháp luật Việt Nam với tiêu chuẩn của Công ước 87, gồm [5]:

i) Quy định tất cả các đơn vị sử dụng lao động phải đóng kinh phí công đoàn $(2 \%)$, trái với các nguyên tắc về tự nguyện và đại diện theo Công ước 87 và trái với nguyên tắc không can thiệp theo Công ước 87.

ii) Quy định hỗ trợ tài chính cho công đoàn từ ngân sách nhà nước và quy định cơ quan nhà nước có quyền thanh tra, kiểm tra tài chính công đoàn không phù hợp với quyền tự chủ về tài của công đoàn theo tiêu chuẩn quốc tế.

- Quyền tự chủ của công đoàn trong việc xây dựng điều lệ, nguyên tắc tổ chức và hoạt động.

Bộ luật lao động và Luật công đoàn không quy định cụ thể, chi tiết về điều lệ và nguyên tắc tổ chức hoạt động của công đoàn. Điều lệ Công đoàn Việt Nam do Đại hội Công đoàn Việt Nam thông qua. Điều này được coi là phù hợp với tiêu chuẩn quốc tế về quyền tự do hiệp hội.

Tuy nhiên, Bộ luật lao động và Luật Công đoàn có các quy định cụ thể thẩm quyền của công đoàn cấp cơ sở và cấp trên trực tiếp của cơ sở. Theo các quy định này, dường như công đoàn cơ sở mới được coi là cấp công đoàn trực tiếp thực hiện vai trò đại diện, bảo vệ quyền lợi 
của người lao động (NLĐ) trong quan hệ lao động, Công đoàn cấp trên chỉ hỗ trợ công đoàn cơ sở thực hiện những nhiệm vụ trên và thực hiện thêm những nhiệm vụ với tư cách là tổ chức chính trị - xã hội trong hệ thống chính trị [6]. So sánh với các tiêu chuẩn của Công ước 87, những vấn đề về cơ cấu tổ chức nội bộ của công đoàn thuộc về quyền tự chủ, tự quản của công đoàn, nên sẽ do công đoàn quyết định chứ không phải Nhà nước quyết định thông qua các quy định của pháp luật. Vì vậy, quy định này trong pháp luật lao động Việt Nam cũng bị coi là không tương thích với tiêu chuẩn quốc tế.

- Về các quy định bảo vệ người lao động và công đoàn trước các hành vi phân biệt đối xử chống công đoàn.

Bộ luật lao động năm 2012, Luật Công đoàn năm 2012 và các văn bản pháp luật liên quan đã có một số quy định cụ thể cấm phân biệt đối xử chống công đoàn [7]. Những quy định này được coi là bước tiến đáng kể của pháp luật liên quan đến việc bảo vệ người lao động và cán bộ công đoàn trước các hành vi phân biệt đối xử vì lý do công đoàn. Tuy nhiên, so với các yêu cầu của Công ước 98 thì vẫn còn một số hạn chế, như: i) Thiếu định nghĩa về phân biệt đối xử chống công đoàn; ii) Các quy định cấm phân biệt đối xử chống công đoàn của Bộ luật lao động và Luật Công đoàn còn khá chung chung; iii) Thủ tục giải quyết tranh chấp về phân biệt đối xử chống công đoàn không rõ ràng và không thống nhất; chỉ quy định về chế tài hành chính đối với hành vi phân biệt đối xử chống công đoàn (Theo yêu cầu của Công ước 98 là phải áp dụng chế tài hình sự đối với hành vi vi phạm này).

- Về quy định bảo vệ công đoàn không bị can thiệp, thao túng bởi người sử dụng lao động.

Mặc dù Bộ luật lao động và Luật công đoàn đã có những quy định nhằm đảm bảo công đoàn không bị can thiệp, thao túng bởi người sử dụng lao động [8] nhưng so với tiêu chuẩn quốc tế thì các quy định của pháp luật Việt Nam vẫn còn một số hạn chế, như: i) Chưa có định nghĩa về khái niệm can thiệp, thao túng công đoàn; ii) Chưa có quy định rõ ràng và cụ thể về bảo vệ công đoàn không bị can thiệp, thao túng bởi người sử dụng lao động, thậm chí một số quy định vô tình tạo điều kiện cho người sử dụng lao động can thiệp, thao túng công đoàn (Điều 192 Bộ luật lao động); iii) Các quy định về giải quyết khiếu nại, khiếu kiện về hành vi can thiệp thao túng công đoàn còn rất hạn chế, không rõ ràng và không thống nhất; iv) Chưa có quy định về chế tài cũng như biện pháp khắc phục hậu quả của hành vi can thiệp, thao túng công đoàn.

\section{Thư hai, về thuoong luợng tập thể.}

Lần đầu tiên các quy định về "thương lượng tập thể” được quy định cụ thể, có tính hệ thống thành một mục của Bộ luật lao động (Mục 2 Chương V). Các quy định về thương lượng tập thể trong Bộ luật lao động bao gồm các nội dung: mục đích của thương lượng tập thể; nguyên tắc thương lượng tập thể; quyền yêu cầu thương lượng tập thể; đại diện thương lượng tập thể; nội dung thương lượng tập thể; quy trình thương lượng tập thể; trách nhiệm của tổ chức công đoàn, tổ chức đại diện người sử dụng lao động và cơ quan quản lý nhà nước về lao động trong thương lượng tập thể. Nhìn chung các quy định này đã phục vụ cơ bản nhu cầu thương lượng, ký kết thỏa ước lao động tập thể trong các doanh nghiệp và giải quyết các vấn đề phát sinh trong quan hệ lao động. Tính đến tháng 11/2017, cả nước đã thành lập được 126.313 tổ chức công đoàn cơ sở với hơn 10 triệu đoàn viên [9]. Theo đánh giá của Tổng Liên đoàn lao động Việt Nam: "Công đoàn đã tích cực tham gia xây dưng chính sách, pháp luật liên quan đến người lao động; nhiều chủ truoong, chính sách của Đảng, Nhà nước về xây dựng giai cấp công nhân và tổ chức Công đoàn đurợc cu thể hóa, đi vào cuộc sống; vai trò Công đoàn tham gia xây dưng quan hẹ lao động hài hòa, ổn định và tiến bộ trong doanh nghiệp tiếp tuc dược khẳng định, góp phần tạo môi truờng thuận lợi cho sản xuất, kinh doanh phát triển, giũu vĩng an ninh, trật tư, an toàn xã hội. Hoạt động tuyên truyền giáo duc tạo được súc lan tóa trong hẹ thống tổ chức Công đoàn. Phong trào thi đua yêu nuớc trong công nhân, viên chưc, lao động có sụ chuyển biến tích cưc, góp phần quan trọng thúc đẩy kinh tế - xã họi phát triển. Công tác tập hợp quần chúng đạt nhiều kết quả, 
thu hút đông đảo nguời lao động gia nhập và tham gia hoạt động công đoàn; mô hình tồ chức bộ máy, chất lượng đội ngũ cán bộ công đoàn được quan tâm hoàn thiện..." [10].

Các tổ chức đại diện của người sử dụng lao động cũng đã có những hoạt động thiết thực, hiệu quả trong việc bảo vệ quyền và lợi ích hợp pháp của người sử dụng lao động, hài hòa lợi tích trong quan hệ lao động, phát triển thị trường lao động và góp phần tích cực trong phát triển kinh tế - xã hội Việt Nam.

Triển khai thực hiện các quy định về quyền tự do hiệp hội và thương lượng tập thể của Bộ luật lao động năm 2012, Trong giai đoạn 2013 2018 (Nhiệm kỳ Đại hội Công đoàn Việt Nam lần thứ XI), trong cả nước đã ký kết được 27.866 bản thỏa ước lao động tập thể, trong đó, có $10,72 \%$ thỏa ước đạt loại $\mathrm{A}, 16,7 \%$ đạt loại B, 28,3\% đạt loại C [9].

Tuy nhiên, so với tiêu chuẩn lao động quốc tế và yêu cầu của CPTPP về vấn đề này thì luật thực định và thực tiễn thi hành pháp luật về thương lượng tập thể ở nước ta vẫn còn một số hạn chế, tồn tại như sau:

- Về nghĩa vụ thương lượng thiện chí: Một trong những nguyên tắc thương lượng tập thể được quy định tại Khoản 1 Điều 67 Bộ luật lao động năm 2012 là nguyên tắc "thiện chí". Tuy nhiên, Bộ luật lao động lại không có quy định cụ thể thế nào là thiện chí trong thương lượng tập thể. Vì vậy, việc triển khai thực hiện quy định này gặp khó khăn trên thực tế và không thống nhất được cách xác định những hành vi vi phạm nghĩa vụ thương lượng thiện chí.

- Việc quy định công đoàn cấp trên trực tiếp được nhiên trở thành người đại diện cho người lao động tại các doanh nghiệp chưa có công đoàn cơ sở, ngoài việc chưa phù hợp với tiêu chuẩn quốc tế về quyền tự do hiệp hội như đã đề cập trên đây, quy định này còn trái với nguyên tắc tự nguyện trong thương lượng tập thể được quy định tại Công ước số 98 của ILO và CPTPP.

- Khoản 1 Điều 69 Bộ luật lao động năm 2012 chỉ quy định chủ thể và trình tự, thủ tục đối thương lượng tập thể cấp doanh nghiệp và cấp ngành. Mặc dù tại Điều 73 Bộ luật lao động có mở ra các phạm vi thương lượng tập thể khác, song giao cho Chính phủ quy định chi tiết. Quy định như vậy chưa phù với nguyên tắc tự nguyện của thương thương tập thể theo tiêu chuẩn quốc tế (theo tiêu chuẩn quốc tế, các bên liên quan được toàn quyền lựa chọn cấp thương lượng, bao gồm cấp quốc gia, khu vực hoặc cấp ngành hoặc bất kỳ cấp nào mà họ mong muốn. Luật pháp không nên có quy định thương lượng tập thể chỉ được tiến hành ở một số cấp xác định cụ thể).

- Về giải quyết tranh chấp tập thể về lợi ích tập thể và thúc đẩy thương lượng tập thể: Theo quy định tại Điều 204 Bộ luật lao động, thủ tục trọng tài được áp dụng bắt buộc đối với tất cả các tranh chấp lợi ích. Điều này là không phù hợp với tiêu chuẩn quốc tế về tự do liên kết và thương lượng tập thể (theo tiêu chuẩn quốc tế, trọng tài bắt buộc chỉ được áp dụng đối với khu vực dịch vụ thiết yếu hoặc thương lượng tập thể lần đầu). Hơn nữa, thủ tục hòa giải được thực hiện bởi Hòa giải viên lao động và thủ tục hòa giải do Hội đồng trọng tài lao động tiến hành không hề có sự khác biệt. Điều này cho thấy theo quy định của Bộ luật lao động hiện hành, việc giải quyết tranh chấp lao động tập thể về lợi ích phải trải qua hai bước hòa giải bắt buộc, quy định này không thúc đẩy mà thực chất là cản trở việc giải quyết tranh chấp lao động tập thể về lợi ích và thương lượng tập thể trên thực tế, không phù hợp với tiêu chuẩn quốc tế về vấn đề này.

\subsection{Xóa bỏ moi hình thức lao động cuỡng búc và lao động bắt buộc}

Thứ nhất, Bộ luật lao động năm 2012 đã có một số nội dung tương thích với tiêu chuẩn quốc tế về lao động cưỡng bức, như: i) Đã có quy định về khái niệm cuỡng bức lao động tại Khoản 10 Điều 3; ii) Đã có quy định về nghiêm cấm hành vi cưỡng bức lao động tại Khoản 3 Điều 8, Khoản 1 Điều 183; iii) Quy định quyền đơn phương chấm dứt hợp đồng lao động của người lao động trong trường hợp bị cưỡng bức lao động tại Khoản 1 Điều 37. 
Thư hai, những điểm còn chưa tương thích:

- Khái niệm cuỡng búc lao động được quy định tại Khoản 3 Điều 10 Bộ luật lao động chưa đảm bảo đầy đủ các tiêu chí về lao động cưỡng bức theo tiêu chuẩn quốc tế được quy định tại Công ước số 29 (năm 1930) của ILO. Điều này thể hiện ở hai khía cạnh sau: i) Quy định tại Khoản 10 Điều 3 Bộ luật lao động chủ yếu nhấn mạnh yếu tố không tự nguyện là do việc dùng vũ lực hoặc đe dọa dùng vũ lực, chưa đề cập những dạng ép buộc, cưỡng bức khác; ii) Thuật ngữ "thủ đoạn khác" chưa được giải thích một cách rõ ràng nên rất khó xác định; iii) Cùng với quy định về phạm vi điều chỉnh của Bộ luật lao động, khái niệm lao động cưỡng bức theo Bộ luật lao động Việt Nam được nhìn nhận với phạm vi rất hẹp so với quy định của Công ước số 29 về vấn đề này (chỉ bị coi là lao động cưỡng bức khi một người phải thực hiện những công việc hợp pháp trái với ý muốn của họ, không bao gồm trường hợp một người phải thực hiện những công việc bất hợp pháp trái ý muốn của họ) $)^{5}$.

- Điều 107 Bộ luật lao động quy định người sử dụng lao động có quyền yêu cầu người lao động làm thêm giờ trong một số trường hợp nhất định vào bất kỳ ngày nào mà NLĐ không được từ chối. Đó thường là những trường hợp về thực hiện nhiệm vụ quốc phòng, an ninh trong tình trạng khẩn cấp hoặc những trường hợp khẩn cấp khác liên quan đến tính mạng, sức khỏe, tài sản của cơ quan, tổ chức, cá nhân ${ }^{6}$. Nếu đơn thuần nhìn từ sự cần thiết do tính khẩn

\footnotetext{
5 Theo Công ước số 29, lao động cưỡng bức không được xác định theo tính chất của công việc (có thể hợp pháp hoặc không hợp pháp theo luật quốc gia) mà phải theo tính chất của mối quan hệ giữa người thực hiện công việc và người hưởng lợi từ công việc.

${ }^{6}$ Điều 107 Bộ luật lao động quy định:

"Người sủ dụng lao động có quyền yêu cầu nguời lao động làm thêm giờ vào bất kỳ ngày nào và người lao động không được tù chối trong các truờng hơp sau đây:

1. Thưc hiện lệnh động viên, huy động bảo đảm nhiệm vu quốc phòng, an ninh trong tình trạng khẩn cấp về quốc phòng, an ninh theo quy định của pháp luạt;

2. Thực hiện các công việc nhằm bảo vệ tính mạng con người, tài sản của co quan, tổ chức, cá nhân trong phòng ngì̀a và khắc phuc hậu quả thiên tai, hỏa hoạn, dịch bệnh và thảm họ".
}

cấp của tình trạng gây ra cần huy động người lao động làm thêm giờ thì quy định tại Điều 107 Bộ luật lao động là cần thiết, tích cực. Tuy nhiên, nếu so sánh với các tiêu chuẩn quốc tế về lao động cưỡng bức và lao động bắt buộc thì quy định của Bộ luật lao động năm 2012 về những trường hợp người sử dụng lao động có quyền huy động NLĐ làm thêm giờ mà người lao động không được từ chối là quá rộng so với quy định về các trường hợp khẩn cấp được phép huy động lao động cưỡng bức tại Khoản 2 Điều 2 của Công ước số 29 (chỉ cho phép lao động bắt buộc trong các trường hợp khẩn cấp, trong khoảng thời gian đặc biệt trong chiến tranh hoặc thiên tai hoặc nguy cơ thiên tai và trong các trường hợp nguy hiểm tới sự an toàn của một phần hoặc toàn nhân loại) [11] .

2.3. Xóa bỏ có hiệu quả lao động trẻ em và nghiêm cấm các hình thức lao động trẻ em tồi tệ nhất

Thư nhất, về tuổi tối thiểu được đi làm việc

Các quốc gia phê chuẩn Công ước số 138 cam kết theo đuổi chính sách quốc gia, nhằm bảo đảm thật sự việc bãi bỏ lao động trẻ em và nâng dần tuổi tối thiểu được đi làm việc hoặc được lao động tới độ tuổi mà các thiếu niên có thể phát triển đầy đủ nhất về thể lực và trí lực. Cụ thể hơn, tuối tối thiểu được đi làm việc không được dưới độ tuổi kết thúc chương trình giáo dục bắt buộc và bất kỳ trường hợp nào cũng không được dưới 15 tuổi; Các quốc gia thành viên mà nền kinh tế và các phương tiện giáo dục chưa phát triển đầy đủ thì, sau khi tham khảo ý kiến các tổ chức hữu quan nếu có, của người sử dụng lao động và của người lao động có thể ghi mức tối thiểu là 14 tuổi trong giai đoạn đầu; Đối với mọi loại việc làm hoặc loại lao động nào mà tính chất hoặc điều kiện tiến hành có thể có hại cho sức khỏe, an toàn hoặc phẩm hạnh của thiếu niên, thì mức tối

\footnotetext{
${ }^{7}$ Observation (CEACR) - adopted 2013, published 103rd ILC session (2014) C029 - Forced Labour Convention, 1930 (No. 29) -Viet Nam,

http://www.ilo.org/dyn/normlex/en, mục VII.
} 
thiểu không được dưới 18 tuổi. Công ước cũng quy định việc xác định tuổi lao động trong những trường hợp đặc biệt.

Bộ luật lao động Việt Nam có khá nhiều quy định tương thích với các tiêu chuẩn quốc tế nêu trên, như: i) Quy định người lao động là người đủ 15 tuổi trở lên (Khoản 1 Điều 3); ii) Quy định người lao động chưa thành niên là người dưới 18 tuổi (Điều 161); iii) Quy định không được sử dụng người lao động chưa thành niên làm những công việc nặng nhọc, độc hại, nguy hiểm hoặc chỗ làm việc, công việc ảnh hướng xấu tới nhân cách của họ theo danh mục do Bộ Lao động - Thương binh và Xã hội chủ trì, phối hợp với Bộ $\mathrm{Y}$ tế ban hành (Khoản 1 Điều 163); iv) Quy định chỉ được sử dụng người từ đủ 13 tuổi đến dưới 15 tuổi làm các công việc nhẹ theo danh mục do Bộ Lao động Thương binh và Xã hội quy định (Khoản 1 Điều 164); v) Quy định khi sử dụng người từ đủ 13 tuổi đến dưới 15 tuổi thì người sử dụng lao động phải tuân theo các điều kiện chặt chẽ (Khoản 2 Điều 164); vi) Quy định không được sử dụng người dưới 13 tuổi làm việc trừ một số công việc cụ thể do Bộ Lao động - Thương binh và Xã hội quy định và khi sử dụng người dưới 13 tuổi làm việc thì phải tuân các điều kiện chặt chẽ (Khoản 3 Điều 164); vii) Quy định người chưa thành niên từ đủ 15 tuổi đến dưới 18 tuổi không được làm việc quá 08 giờ trong 01 ngày và 40 giờ trong 01 tuần; người dưới 15 tuổi không được làm việc quá 04 giờ trong 01 ngày và 20 giờ trong 01 tuần và không được sử dụng làm thêm giờ, làm việc vào ban đêm (Khoản 2 Điều 163); viii) Quy định người từ đủ 15 tuổi đến dưới 18 tuổi được làm thêm giờ, làm việc vào ban đêm trong một số nghề và công việc theo quy định của Bộ Lao động - Thương binh và Xã hội (Khoản 3 Điều 163)...

Tuy nhiên, vẫn còn những nội dung chưa tương thích giữa Bộ luật lao động năm 2012 và Công ước số 138. Cụ thể là: i) Khái niệm "người lao động" theo quy định tại Khoản 1 Điều 3 Bộ luật lao động năm 2012 đã thu hẹp đáng kể phạm vi "người lao động" do chính Bộ luật lao động điều chỉnh và không thống nhất với các quy định về sử dụng lao động là người dưới 15 tuổi tại Điều 163, Điều 164 Bộ luật lao động; ii) Bộ luật lao động năm 2012 mới chỉ quy định về thời giờ làm việc đối với người dưới 15 tuổi nói chung mà chưa có quy định về thời giờ làm việc đối với người dưới 13 tuổi; chưa có quy định cụ thể về thời giờ làm thêm của người từ đủ 15 tuổi đến dưới 18 tuổi; iii) Có sự chưa rõ ràng trong việc xác định thế nào là trẻ em lao động trái pháp luật, trẻ em bị bóc lột sức lao động.

Thư hai, về nghiêm cấm và hành động khẩn cấp xóa bỏ các hình thức lao động trẻ em tồi tệ nhất

Công ước số 182 yêu cầu các quốc gia thành viên phải xóa bỏ ngay 4 hình thức lao động trẻ em (người dưới 18 tuổi) tồi tệ nhất, gồm: i) Mọi hình thức nô lệ hay tương tự nô lệ như buôn bán và vận chuyển trẻ em, gán nợ và lao động nô lệ và lao động cưỡng bức trong đó có tuyển mộ cưỡng bức trẻ em tham gia vào các xung đột vũ trang; ii) Sử dụng, dụ dỗ hoặc lôi kéo trẻ em vào hoạt động mại dâm, sản xuất các sản phẩm phim ảnh khiêu dâm hoặc biểu diễn khiêu dâm; iii) Sử dụng, dụ dỗ hoặc lôi kéo trẻ em vào các hoạt động bất hợp pháp, đặc biệt vào mục đích sản xuất và vận chuyển chất ma tuý như được nêu tại các hiệp định quốc tế; iv) Những công việc mà tính chất hoặc các điều kiện của nó có thể xâm hại đến sức khoẻ, an toàn và đạo đức của trẻ em.

Những quy định tại Mục 1 Chương XI Bộ luật lao động năm 2012 và các văn bản quy định chi tiết, hướng dẫn thi hành về cơ bản đã đáp ứng yêu cầu của Công ước số 182. Điều 165 Bộ luật lao động năm 2012 quy định cấm sử dụng người chưa thành niên làm công việc gây tổn hại sức khỏe, an toàn hoặc đạo đức người chưa thành niên và cấm sử dụng người chưa thành niên làm việc tại sòng bạc, quán bar; vũ trường, phòng hát karaoke, khách sạn, nhà nghỉ, phòng tắm hơi, phòng xoa bóp; nơi làm việc khác gây tổn hại đến sức khỏe, sự an toàn và đạo đức của trẻ em và giao Bộ Lao động - 
Thương binh và Xã hội quy định danh mục chi tiết các công việc nêu trên.

Vấn đề còn tồn tại duy nhất trong quy định của Bộ luật lao động là chưa khẳng định rõ việc cấm cụ thể những hình thức lao động trẻ em tồi tệ nhất như định nghĩa của Công ước số 182.

\subsection{Xóa bỏ phân biệt đối xủ trong công việc}

Xóa bỏ phân biệt đối xử trong công việc được ILO quy định tại Công ước số 111 (năm 1958). Theo đó, các quốc gia thành viên phải áp dụng các biện pháp phù hợp với điều kiện và thực tiễn của nước mình nhằm đảm bảo sự bình đẳng về cơ hội và chế độ đãi ngộ liên quan đến nghề nghiệp và việc làm trên cơ sở xóa bỏ mọi sự phân biệt đối xử có liên quan.

Công ước số 111 xác định phạm vi của phân biệt đối xử có thể "dựa trên chủng tộc, màu da, giới tính, tôn giáo, chính kiến, dòng dõi dân tộc hoặc nguồn gốc xã hội". "Phân biệt đối xử" bao gồm: i) Mọi sự phân biệt, loại trừ hoặc ưu đãi dựa trên chủng tộc, màu da, giới tính, tôn giáo, chính kiến, dòng dõi dân tộc, hoặc nguồn gốc xã hội, có tác động trong việc làm hoặc nghề nghiệp; ii) Mọi sự phân biệt, loại trừ hoặc ưu đãi khác nhằm triệt bỏ hoặc làm phương hại sự bình đẳng về cơ may hoặc đối xử mà nước thành viên hữu quan sẽ có thể chỉ rõ sau khi tham khảo ý kiến các tổ chức đại diện của người sử dụng lao động và người lao động, nếu có và của các tổ chức thích hợp khác.

Các quốc gia thành viên của ILO đã phê chuẩn Công ước sẽ phải áp dụng các biện pháp thích hợp để phát triển, thực thi pháp luật, đảm bảo việc tuân thủ Công ước.

Bộ luật lao động năm 2012 đã có một số nội dung tương thích với tiêu chuẩn quốc tế về chống phân biệt đối xử trong công việc, như: i) Đã quy định nhà nước có chính sách bảo đảm nguyên tắc bình đẳng giới; quy định chế độ lao động và chính sách xã hội nhằm bảo vệ lao động nữ, lao động là người khuyết tật, người lao động cao tuổi, lao động chưa thành niên (Điều 4); ii) Đã quy định nghiêm cấm phân biệt đối xử về giới tính, dân tộc, màu da, thành phần xã hội, tình trạng hôn nhân, tín ngưỡng, tôn giáo, nhiễm HIV, khuyết tật hoặc vì lý do thành lập, gia nhập và hoạt động công đoàn; ngược đãi , quấy rối tình dục tại nơi làm việc (Khoản 1, Khoản 2 Điều 8); iii) Đã quy định người lao động có quyền làm việc, tự do lựa chọn việc làm, nghề nghiệp, học nghề, nâng cao trình độ nghề nghiệp và không bị phân biệt đối xử (Khoản 1 Điều 5); iv) Đã quy định nguyên tắc "Người sử dụng lao động phải bảo đảm trả lương bình đẳng, không phân biệt giới tính đối với người lao động làm công việc có giá trị như nhau" (Khoản 3 Điều 90); v) Đã có những quy định riêng về lao động nữ nhằm thúc đẩy bình đẳng giới; vi) Đã có quy định về quấy rối tình dục (Điểm c Khoản 1 Điều 37, Khoản 4 Điều 182 và Khoản 1 Điều 183).

Tuy nhiên, nếu thực hiện đầy đủ các quy chuẩn quốc tế về vấn đề này thì quy định của pháp luật lao động Việt Nam còn một số tồn tại sau: i) Chưa có định nghĩa về phân biệt đối xử; ii) Phạm vi nghiêm cấm phân biệt đối xử của Bộ luật lao động năm 2012 hẹp hơn so với phạm vi nghiêm cấm phân biệt đối xử của Công ước số 111 (thiếu việc nghiêm cấm phân biệt đối xử về nguồn gốc xã hội, phân biệt đối xử về chính kiển); iii) Quy địnhđộ tuổi nghỉ hưu khác nhau giữa nam và nữ; iv) Chưa có định nghĩa về quấy rối tình dục cũng như chưa có quy định để giải quyết và phòng ngừa quấy rối tình dục tại nơi làm việc; v) Quy định về danh mục công việc cấm sử dụng lao động nữ đi ngược lại với cách tiếp cận đối với việc không phân biệt đối xử trên tất cả khía cạnh việc làm và nghề nghiệp...

\section{Hoàn thiện pháp luật lao động nhằm đảm bảo sự phù hợp với quy định của Hiệp định Đối tác toàn diện và tiến bộ xuyên Thái Bình Dương}

\subsection{Quyền tư do hiẹp hội và thực hiện có hiệu quả quyền thuoong luợng tập thể}

Thư nhất, về quyền tụ do hiệp hội

Một là, cần sửa đổi quy định về đối tượng người lao động được tự do thành lập, gia nhập 
và hoạt động công đoàn theo hướng mở rộng đến cả các đối tượng sau: i) Người lao động không phải là người có quốc tịch Việt Nam làm việc tại Việt Nam; ii) Người lao động trong khu vực phi chính thức, lao động tự do, không có quan hệ việc làm; iii) Người lao động làm việc cho cá nhân, hộ gia đình.

Hai là, cần sửa đổi, bổ sung Bộ luật lao động năm 2012 theo hướng chấp nhận có thể tồn tại nhiều tổ chức công đoàn đại diện cho người lao động bên cạnh hệ thống Tổng Liên đoàn lao động Việt Nam; bãi bỏ quy định ở những nơi chưa thành lập tổ chức công đoàn cơ sở, công đoàn cấp trên trực tiếp cơ sở đương nhiên thực hiện vai trò đại diện cho tập thể người lao động.

$B a$ là, cần quy định cơ chế để người lao động có thể đăng ký thành lập công đoàn với Nhà nước theo các điều kiện, trình tự và thủ tục hợp lý, công khai và minh bạch.

Bốn là, cần bổ sung những quy định mang tính nguyên tắc về bầu cử công đoàn trong văn bản pháp luật của Nhà nước.

Năm là, khi thực hiện triệt để quyền tự do công đoàn theo CPTPP, cần bãi bỏ các quy định của Bộ luật lao động năm 2012 và Luật công đoàn năm 2012 về việc bắt buộc người sử dụng lao động phải đóng $2 \%$ kinh phí công đoàn; quy định về hỗ trợ tài chính từ ngân sách nhà nước cho công đoàn hoạt động; các quy định về thanh tra, giám sát tài chính công đoàn.

Sáu là, cần bãi bỏ các quy định cụ thể về thẩm quyền của công đoàn các cấp trong Bộ luật lao động và Luật công đoàn (việc xác định thẩm quyền của công đoàn các cấp phụ thuộc vào sự phân công công việc trong nội bộ của từng tổ chức công đoàn).

Bảy là, cần bổ sung các quy định bảo vệ người lao động và công đoàn trước các hành vi phân biệt đối xử chống công đoàn, như: i) Quy định định nghĩa về phân biệt đối xử chống công đoàn; ii) Quy định cụ thể về cấm phân biệt đối xử chống công đoàn của Bộ luật lao động và Luật Công đoàn; iii) Quy định cụ thể, thống nhất về thủ tục giải quyết tranh chấp về phân biệt đối xử chống công đoàn; iv) Quy định chế tài hình sự đối với hành vi vi phạm quy định về cấm phân biệt đối xử chống công đoàn.

Tám là, cần sửa đổi, bổ sung các quy định bảo vệ công đoàn không bị can thiệp, thao túng bởi người sử dụng lao động, như: i) Quy định về khái niệm can thiệp, thao túng công đoàn; ii) Quy định rõ ràng và cụ thể về bảo vệ công đoàn không bị can thiệp, thao túng bởi người sử dụng lao động; iii) Quy định cụ thể, hợp lý hơn về giải quyết khiếu nại, khiếu kiện về hành vi can thiệp thao túng công đoàn; iv) Quy định về chế tài, biện pháp khắc phục hậu quả của hành vi can thiệp, thao túng công đoàn.

\section{Thư hai, về thuoong luợng tập thể}

- Cần bổ sung quy định cụ thể thế nào là thiện chí trong thương lượng tập thể để có thể thuận lợi, thống nhất trong áp dụng và xác định, xử lý được hành vi vi phạm nguyên tắc này.

- Sửa đổi quy định về chủ thể và trình tự, thủ tục đối thương lượng tập thể theo hướng mở rộng phạm vi so với phạm vi cấp doanh nghiệp và cấp ngành như hiện nay.

- Sửa đổi các quy định về trọng tài lao động của Bộ luật lao động năm 2012, trong đó cần đặc biệt chú trọng đến các vấn đề sau: quy định về trọng tài lao động theo đúng bản chất của trọng tài (có quyền ra phán quyết trọng tài); quy định cơ chế trọng tài tự nguyện, ngoại trừ những trường hợp thật cần thiết thì áp dụng cơ chế trọng tài bắt buộc; quy định về mối quan hệ giữa cơ chế trọng tài lao động và các cơ chế khác trong việc giải quyết tranh chấp lao động.

\subsection{Xóa bỏ moi hình thức lao động cuỡng búc và lao động bắt buộc}

Để đảm bảo phù hợp với tiêu chuẩn quốc tế về xóa bỏ mọi hình thức lao động cưỡng bức và lao động bắt buộc, trong thời gian tới Việt Nam cần rà soát, sửa đổi, bổ sung các quy định của pháp luật lao động mà quan trọng nhất là các quy định của Bộ luật lao động năm 2012. Cụ thể như sau:

- Sửa đổi quy định khái niệm "cưỡng bức lao động" quy định tại Khoản 3 Điều 10 Bộ luật lao động theo hướng đảm bảo đầy đủ các tiêu 
chí về lao động cưỡng bức theo tiêu chuẩn quốc tế được quy định tại Công ước số 29 (năm 1930) của ILO. Cụ thể: Khái niệm cần đề cập đầy đủ những dạng ép buộc, cưỡng bức lao động được quy đinh tại Công ước số 29; Khái niệm cần xác định lao động cưỡng bức cả khi một người phải thực hiện những công việc hợp pháp hoặc công việc bất hợp pháp trái với ý muốn của họ.

- Sửa đổi quy định tại Điều 107 Bộ luật lao động theo hướng thu hẹp các trường hợp người sử dụng lao động có quyền yêu cầu người lao động làm thêm giờ trong một số trường hợp nhất định vào bất kỳ ngày nào mà người lao động không được từ chối, đảm bảo chỉ cho phép lao động bắt buộc trong các trường hợp khẩn cấp, trong khoảng thời gian đặc biệt trong chiến tranh hoặc thiên tai hoặc nguy cơ thiên tai và trong các trường hợp nguy hiểm tới sự an toàn của một phần hoặc toàn nhân loại.

\subsection{Xóa bỏ có hiệu quả lao động trẻ em và nghiêm cấm các hình thức lao động trẻ em tồi tệnhất}

\section{Thư nhất, về tuổi tối thiểu được đi làm việc}

- Cần sửa đổi quy định về khái niệm "người lao động" tại Khoản 1 Điều 3 Bộ luật lao động năm 2012 theo hướng bao quát đủ các đối tượng người lao động thuộc đối tượng áp dụng của Bộ luật lao động và bảo đảm thống nhất với các quy định về sử dụng lao động là người dưới 15 tuổi tại Điều 163, Điều 164 Bộ luật lao động.

- Cần bổ sung vào Bộ luật lao động quy định về thời giờ làm việc đối với người dưới 13 tuổi (tức là cần phân biệt thời giờ làm việc của hai nhóm người lao động: Nhóm người lao động đủ 13 tuổi đến dưới 15 tuổi và nhóm người lao động dưới 13 tuổi).

- Cần bổ sung vào Bộ luật lao động quy định cụ thể về thời giờ làm thêm của người từ đủ 15 tuổi đến dưới 18 tuổi.

- Cần có quy định cụ thể thế nào là trẻ em lao động trái pháp luật, trẻ em bị bóc lột sức lao động.
Thư hai, về nghiêm cấm và hành động khẩn cấp xóa bỏ các hình thức lao động trẻ em tồi tệ nhất

Cần bổ sung vào Bộ luật lao động định nghĩa rõ việc cấm cụ thể những hình thức lao động trẻ em tồi tệ nhất như định nghĩa của Công ước số 182, gồm: i) Mọi hình thức nô lệ hay tương tự nô lệ như buôn bán và vận chuyển trẻ em, gán nợ và lao động nô lệ và lao động cưỡng bức trong đó có tuyển mộ cưỡng bức trẻ em tham gia vào các xung đột vũ trang; ii) Sử dụng, dụ dỗ hoặc lôi kéo trẻ em vào hoạt động mại dâm, sản xuất các sản phẩm phim ảnh khiêu dâm hoặc biểu diễn khiêu dâm; iii) Sử dụng, dụ dỗ hoặc lôi kéo trẻ em vào các hoạt động bất hợp pháp, đặc biệt vào mục đích sản xuất và vận chuyển chất ma tuý như được nêu tại các hiệp định quốc tế; iv) Những công việc mà tính chất hoặc các điều kiện của nó có thể xâm hại đến sức khoẻ, an toàn và đạo đức của trẻ em.

\subsection{Xóa bỏ phân biệt đối xử trong công việc}

Để thực hiện đầy đủ các tiêu chuẩn lao động quốc tế về xóa bỏ phân biệt đối xử trong công việc, cần rà soát, sửa đổi, bổ sung các quy định sau:

- Bổ sung định nghĩa về phân biệt đối xử.

- Cần sửa đổi quy định về phạm vi nghiêm cấm phân biệt đối xử của Bộ luật lao động năm 2012, bao gồm cả việc nghiêm cấm phân biệt đối xử về nguồn gốc xã hội, phân biệt đối xử về chính kiến.

- Sửa đổi quy định về tuổi nghỉ hưu theo hướng xác định lộ trình tăng dần tuổi nghỉ hưu của lao động nữ tiếp cận gần hoặc bằng tuổi của lao động nam.

- Bổ sung quy định định nghĩa về quấy rối tình dục cùng với quy định về cơ chế giải quyết và phòng ngừa quấy rối tình dục tại nơi làm việc.

- Cần bãi bỏ quy định về danh mục công việc cấm sử dụng lao động nữ. 


\section{Tài liệu tham khảo}

[1] Hiệp định TPP-CPTPP, http://www.trungtamwto.vn/chuyen-de/tpp.

[2] Nghị định số 45/2010/NĐ-CP ngày 21/4/2010 quy định về tổ chức, hoạt động và quản lý hội; Nghị định số 33/2012/NĐ-CP ngày 13/4/2012 sửa đổi, bổ sung một số điều của Nghị định số 45/2010/NĐ-CP; Thông tư số 13/2013/TT-BNV ngày 16/4/2013 của Bộ Nội vụ quy định chi tiết thi hành Nghị định số $45 / 2010 / \mathrm{NĐ-CP}$ và Nghị định số 33/2012/NĐ-CP.

[3] Công ước số 87 (năm 1948) của ILO.

[4] Điều lệ Công đoàn Việt Nam năm 2013; Văn bản số $238 / H D-T L Đ$ ngày $04 / 3 / 2014$ của Tổng liên đoàn lao động Việt nam hướng dẫn thi hành Điều lệ Công đoàn Việt Nam.

[5] Natsu Nogami, Báo cáo rà soát pháp luật Việt Nam với các tiểu chuẩn lao động quốc tế, Tài liệu kỹ thuật của Văn phòng ILO Hà Nội, 2014.

[6] Bộ luật lao động năm 2012.

[7] Luật công đoàn; Nghị định 95/2013/NĐ-CP ngày 22/8/2013 Quy định xử phạt vi phạm hành chính trong lĩnh vực lao động, bảo hiểm xã hội, đưa người lao động việt nam đi làm việc ở nước ngoài theo hợp đồng (được sửa đổi bởi Nghị định số $88 / 2015 / \mathrm{NĐ}-\mathrm{CP})$.

[8] Nghị định số 88/2015/NĐ-CP ngày 07/10/2015 về sửa đổi, bổ sung một số điều của nghị định số 95/2013/NĐ-CP ngày 22 tháng 8 năm 2013 của chính phủ Quy định xử phạt vi phạm hành chính trong lĩnh vực lao động, bảo hiểm xã hội, đưa người lao động việt nam đi làm việc ở nước ngoài theo hợp đồng.

[9] Nhóm phóng viên, Hoạt động Công đoàn đóng góp vào thành tựu chung của đất nước, www:// nld.com.vn/cong-doan/phien-trong-the-dai-hoicong-doan-viet-nam-lan-thu-xii-

20180925081249731.htm (đăng tải: 25/09/2018 08:13).

[10] Nghị quyết Đại hội Công đoàn Việt Nam lần thứ XII (nhiệm kỳ 2018 - 2023).

[11] Observation (CEACR) - adopted 2013, published 103rd ILC session (2014) C029 - Forced Labour Convention, 1930 (No. 29) - Viet Nam, http://www.ilo.org/dyn/normlex/en, mục VII. 